\title{
Experimental study of the role of physicochemical surface processing on the IN ability of mineral dust particles
}

\author{
D. Niedermeier ${ }^{1}$, S. Hartmann ${ }^{1}$, T. Clauss ${ }^{1}$, H. Wex ${ }^{1}$, A. Kiselev ${ }^{1,2}$, R. C. Sullivan ${ }^{3}$, P. J. DeMott ${ }^{3}$, M. D. Petters ${ }^{3,4}$, \\ P. Reitz $^{5,6}$, J. Schneider ${ }^{5}$, E. Mikhailov ${ }^{7}$, B. Sierau ${ }^{8}$, O. Stetzer $^{8}$, B. Reimann ${ }^{9}$, U. Bundke ${ }^{9}$, R. A. Shaw ${ }^{10}$, \\ A. Buchholz ${ }^{11}$, T. F. Mentel ${ }^{11}$, and F. Stratmann ${ }^{1}$ \\ ${ }^{1}$ Leibniz Institute for Tropospheric Research, Leipzig, Germany \\ ${ }^{2}$ Karlsruhe Institute of Technology, Institute for Meteorology and Climate Research, Eggenstein-Leopoldshafen, Germany \\ ${ }^{3}$ Department of Atmospheric Science, Colorado State University, Fort Collins, Colorado, USA \\ ${ }^{4}$ Department of Marine, Earth, and Atmospheric Sciences, North Carolina State University, Raleigh, North Carolina, USA \\ ${ }^{5}$ Particle Chemistry Department, Max Planck Institute for Chemistry, Mainz, Germany \\ ${ }^{6}$ Institute for Atmospheric Physics, Johannes Gutenberg University, Mainz, Germany \\ ${ }^{7}$ Fock Institute of Physics, St. Petersburg State University, St. Petersburg, Russia \\ ${ }^{8}$ Institute for Atmospheric and Climate Science, ETH Zürich, Zürich, Switzerland \\ ${ }^{9}$ Institute for Atmospheric and Environmental Sciences, Goethe University, Frankfurt, Germany \\ ${ }^{10}$ Department of Physics, Michigan Technological University, Houghton, Michigan, USA \\ ${ }^{11}$ IEK 8: Troposphere, Research Center Jülich, Jülich, Germany
}

Received: 7 June 2011 - Published in Atmos. Chem. Phys. Discuss.: 29 June 2011

Revised: 4 November 2011 - Accepted: 4 November 2011 - Published: 9 November 2011

\begin{abstract}
During the measurement campaign FROST 2 (FReezing Of duST 2), the Leipzig Aerosol Cloud Interaction Simulator (LACIS) was used to investigate the influence of various surface modifications on the ice nucleating ability of Arizona Test Dust (ATD) particles in the immersion freezing mode. The dust particles were exposed to sulfuric acid vapor, to water vapor with and without the addition of ammonia gas, and heat using a thermodenuder operating at $250^{\circ} \mathrm{C}$. Size selected, quasi monodisperse particles with a mobility diameter of $300 \mathrm{~nm}$ were fed into LACIS and droplets grew on these particles such that each droplet contained a single particle. Temperature dependent frozen fractions of these droplets were determined in a temperature range between $-40^{\circ} \mathrm{C} \leq T \leq-28^{\circ} \mathrm{C}$. The pure ATD particles nucleated ice over a broad temperature range with their freezing behavior being separated into two freezing branches characterized through different slopes in the frozen fraction vs. temperature curves. Coating the ATD particles with sulfuric acid resulted in the particles' IN potential significantly decreasing in the first freezing branch $\left(T>-35^{\circ} \mathrm{C}\right)$ and a slight increase in the second branch $\left(T \leq-35^{\circ} \mathrm{C}\right)$. The addition of water vapor after the sulfuric acid coating caused the disappearance
\end{abstract}

of the first freezing branch and a strong reduction of the IN ability in the second freezing branch. The presence of ammonia gas during water vapor exposure had a negligible effect on the particles' IN ability compared to the effect of water vapor. Heating in the thermodenuder led to a decreased IN ability of the sulfuric acid coated particles for both branches but the additional heat did not or only slightly change the IN ability of the pure ATD and the water vapor exposed sulfuric acid coated particles. In other words, the combination of both sulfuric acid and water vapor being present is a main cause for the ice active surface features of the ATD particles being destroyed. A possible explanation could be the chemical transformation of ice active metal silicates to metal sulfates. The strongly enhanced reaction between sulfuric acid and dust in the presence of water vapor and the resulting significant reductions in IN potential are of importance for atmospheric ice cloud formation. Our findings suggest that the IN concentration can decrease by up to one order of magnitude for the conditions investigated. 


\section{Introduction}

Various atmospheric observations of droplet freezing through heterogeneous ice nucleation show that mineral dust particles act effectively as ice nuclei (IN) (Sassen et al., 2003; DeMott et al., 2003a,b; Cziczo et al., 2004; Richardson et al., 2007; Seifert et al., 2010). The reason is that mineral dust largely consist of aluminosilicate clays which display a high ice nucleating ability (Archuleta et al., 2005; Kanji et al., 2008; Zimmermann et al., 2008). Through their ability to nucleate ice, mineral dust particles influence microphysical and dynamical cloud properties, the formation of precipitation, cloud life time, and therefore Earth's climate (Martin, 2000; Sassen et al., 2003; Lohmann and Diehl, 2006; Lohmann and Hoose, 2009).

Mineral dust particles originate from desert and arid regions and can be lifted into the free troposphere during storm events and also due to dry convective mixing (Knippertz et al., 2009). Subsequently, the mineral dust particles can be transported over large distances (Prospero, 1999; DeMott et al., 2003a; Sassen et al., 2003) and undergo aging processes, e.g., through coatings of sulfates and other electrolytes (Posfai et al., 1994; Martin, 2000). As a result of these aging processes, the particle surface and therefore particles' IN ability may change.

Several laboratory studies have been performed to investigate the influence of different acidic coatings on the IN ability of mineral dust particles (e.g., Archuleta et al., 2005; Knopf and Koop, 2006; Cziczo et al., 2009; Eastwood et al., 2009; Niedermeier et al., 2010). In the deposition nucleation mode below water saturation it was found that sulfuric acid coating on alumina-silicate and Arizona Test Dust (ATD) particles reduced the IN ability compared to the pure particles (Archuleta et al., 2005; Cziczo et al., 2009; Eastwood et al., 2009). In contrast, Knopf and Koop (2006) did not observe a clear difference between sulfuric acid coated and pure ATD particles. Furthermore, sulfuric acid coating on aluminum oxide (corundum) particles altered the IN ability only slightly and the same coating on iron oxide (hematite) particles even led to an enhanced IN ability compared to the untreated particles (Archuleta et al., 2005). But the question remains whether the coatings only cover the particle surface so that ice active surface features are concealed and/or lead to particle surface modifications due to chemical reactions impairing the particles' IN ability. The latter case would be visible in the immersion freezing mode because soluble coating material should most likely dissolve in the droplet and therefore be removed from the particle surface. For example, Sullivan et al. (2010b) observed that nitric acid coatings on ATD particles impaired deposition nucleation below water saturation. In contrast, immersion freezing was not affected leading to the conclusion that nitric acid did not irreversible alter the particle surface. But the question remains whether such a behavior also appears for other acidic coatings like sulfuric acid. As strong indications exist that immersion freezing is one of the important or maybe even the most important atmospheric ice formation mechanism (Ansmann et al., 2008; Connolly et al., 2009; Hoose et al., 2010; Wiacek et al., 2010; de Boer et al., 2011), and as the influences of particle coatings on the IN ability in the immersion freezing mode are not well understood and quantified, more investigations are needed.

During the first "FReezing Of duST" campaign (FROST 1), Niedermeier et al. (2010) investigated the influence of acidic and neutralized acidic coatings (succinic and sulfuric acid, ammonium sulfate) on the IN ability of ATD particles in the immersion freezing mode at the laminar flow diffusion cloud chamber LACIS (Leipzig Aerosol Cloud Interaction Simulator; Hartmann et al., 2011; Stratmann et al., 2004). LACIS was used to investigate the influence of size selected, quasi monodisperse dust particles on immersion freezing. In particular, we note that in this method, only one particle is immersed in each droplet. It was found that the applied coatings led to particle surface modifications, decreasing the ice nucleation ability of the treated particles in different ways. In case of sulfuric acid coatings, the IN ability decreased with increasing coating amount and the ammonium sulfate coated particles showed the lowest IN ability within the temperature range investigated. In contrast, the IN ability of succinic acid coated ATD particles was similar to that of the pure ATD particles.

During the measurement campaign FROST 2, which took place in March/April 2009 at LACIS, we expanded the investigations concerning the influence of various surface treatments on the IN ability of ATD particles. Similar to FROST 1, size selected, quasi monodisperse submicron particles were considered for coating with different amounts of sulfuric acid to explore to what extent the increase of coating amount leads to an increase of surface modifications thus altering the IN potential of the particles. Furthermore, the highest temperature considered was increased to $-28^{\circ} \mathrm{C}$ compared to $-34^{\circ} \mathrm{C}$ for FROST 1. In addition, the sulfuric acid coated particles were exposed to water vapor with and without the addition of ammonia gas in order to evaluate which process is more important for IN ability reduction: sulfuric acid neutralization by ammonia or the acceleration of the reaction between sulfuric acid and mineral dust due to the presence of water. Finally, the sulfuric acid coated (including the additional water vapor and ammonia exposure) and pure ATD particles were treated thermally to investigate if additional heat leads to the evaporation of the coating material, resulting in the ice nucleation potential of the particles being restored.

Our study is related to the investigations described in Sullivan et al. (2010a) and Reitz et al. (2011). Sullivan et al. (2010a) determined the IN ability of the particles in the deposition nucleation and immersion/condensation freezing mode at two distinct temperatures: $-25^{\circ} \mathrm{C}$ and $-30^{\circ} \mathrm{C}$ using the Continuous Flow thermal gradient Diffusion Chamber (CFDC). The CFDC measurements clearly show that for 
all coatings the ice nucleation ability of the coated ATD particles was lowered compared to pure ATD in both the deposition and the immersion/condensation mode. However, the deposition mode turned out to be significantly more affected, implying that soluble material on the particle surface goes into solution when particles become activated, and possibly reveals covered surface features (Sullivan et al., 2010a). Reitz et al. (2011) performed the chemical characterization of the differently treated particles using the Compact TimeOf-Flight Aerosol Mass Spectrometer (C-ToF-AMS). They suggest that the different treatments lead to different chemical reactions on the particle surface modifying the ATD particle surface (more details are presented in the results section). In our study we focus on the investigations carried out with LACIS. In contrast to Sullivan et al. (2010a), we investigated the IN ability of the particles in the immersion freezing mode determining the freezing behavior in the temperature range between $-28^{\circ} \mathrm{C}$ and $-40^{\circ} \mathrm{C}$. The larger temperature range and the results concerning the chemical characterization of the particles being available, allow us to illustrate more clearly how physicochemical surface modifications influence the IN ability of particles, e.g., the effect of water vapor exposure to the sulfuric acid coated particles on their IN ability.

\section{Experimental methods}

\subsection{Particle generation and general setup}

The particle generation procedure was similar to that used during the FROST 1 campaign (Niedermeier et al., 2010). In all experiments ATD (ISO 12103-1, A1 Ultrafine Test Dust, Powder Technology Inc., Burnsville, Minnesota, USA) was used. It features typical properties of desert dust common in the Southwestern USA. Broadley et al. (2011) performed a X-ray diffraction analysis of ATD ("nominal 0-3 micron ATD”, Powder Technology Inc., Burnsville, MN, USA) and showed that the bulk ATD material mainly consists of silicate minerals $(5.6 \%$ carbonate, $33.2 \mathrm{wt} \%$ feldspar, $7.5 \mathrm{wt} \%$ illite, $10.2 \mathrm{wt} \%$ illite-smectite mixed layer, $2 \mathrm{wt} \%$ kaolinite, $17.1 \mathrm{wt} \%$ quartz and $24.4 \mathrm{wt} \%$ other clay minerals). These minerals also include compounds like iron, calcium, magnesium, etc. (Vlasenko et al., 2005). The ATD particles were dispersed using a fluidized bed generator (TSI 3400A, TSI Inc., St. Paul, Minnesota, USA) (see Fig. 1). As the result of friction in the fluidized bed, the particles were multiply charged and a self-built Corona discharger was used to discharge them partially. Note that the corona discharger did not influence the IN ability of the particles (Niedermeier et al., 2010). Downstream of the corona discharger, particles with an aerodynamic diameter larger than $560 \mathrm{~nm}$ were removed from the aerosol flow using a Micro-Orifice UniformDeposit Impactor (MOUDI Model 100R, MSP Corporation, Shoreview, Michigan, USA). A Krypton 85 neutralizer was applied to establish a bipolar equilibrium charge distribution on the particles.

Subsequently, the ATD particles could be processed in various ways. First, particles were coated with sulfuric acid in a vapor diffusion tube which contained a reservoir filled with sulfuric acid. The tube was surrounded by a water jacket, the temperature of which was controlled by a thermostat (HAAKE C25P, HAAKE GmbH, Karlsruhe, Germany). Three temperatures were applied during the experiments $\left(45^{\circ} \mathrm{C}, 70^{\circ} \mathrm{C}\right.$, and $\left.85^{\circ} \mathrm{C}\right)$, resulting in three different amounts of sulfuric acid on the particles.

For the production of ammonium sulfate coatings, the ATD particles were first coated with sulfuric acid at $70{ }^{\circ} \mathrm{C}$ and subsequently passed over a water bath at room temperature (about $25^{\circ} \mathrm{C}$ ) where the aerosol was humidified. Then, ammonia gas (10 ppm, Air liquide GmbH, Leipzig, Germany) was added to the aerosol flow at a flow rate of $0.501 \mathrm{~m}^{-1}$. In a three meter reaction path (about $10 \mathrm{~s}$ residence time) the neutralization of the particulate sulfuric acid by the ammonia gas could take place. After that the aerosol flow was dried using a diffusion dryer. Additional experiments were performed in a similar way but without the direct addition of ammonia gas to separate the effect of water absorbtion after sulfuric acid coating on the particles' IN ability.

Downstream of the coating device, particles could be passed through a thermodenuder. In its heating section a temperature of $250^{\circ} \mathrm{C}$ was applied. Finally, a DMA (Differential Mobility Analyzer; Knutson and Whitby (1975); type "Vienna Medium") was used to select a quasi-monodisperse particle size fraction. For the freezing experiments, particles with a mobility diameter of $300 \mathrm{~nm}$ were selected.

Downstream of the DMA the aerosol flow was split by a flow divider with one fraction being directly supplied to the Compact Time-Of-Flight Aerosol Mass Spectrometer (CToF-AMS, manufactured by Aerodyne Research Inc., Billerica, Massachusetts, USA, Drewnick et al., 2005; operated from Max Planck Institute for Chemistry, Mainz, Germany) and the Aerosol Time-Of-Flight Mass Spectrometer (ATOFMS, manufactured by TSI Inc., Shoreview, Minnesota, USA, Prather et al., 1994; operated from ETH Zurich, Zurich, Switzerland) in order to characterize the selected particles with respect to their chemical composition. The other fraction of the aerosol flow leaving the DMA was led to a dilution system where particle free air was added. All flows were controlled by mass flow controllers (MKS 1179, MKS Instruments Deutschland $\mathrm{GmbH}$, Munich, Germany) and checked on a daily basis with a bubble flow meter (Gilian ${ }^{\circledR}$ Gilibrator $^{\mathrm{TM}} 2$, Sensidyne Inc., Clearwater, Florida, USA). From the dilution system, the remaining instruments were supplied with their required flows. A Condensation Particle Counter (CPC, GRIMM 5.304, GRIMM Aerosol Technik GmbH \& Co. KG, Ainring, Germany) was used to measure the total particle concentration. The hygroscopic growth and activation behavior of the selected particles were determined 


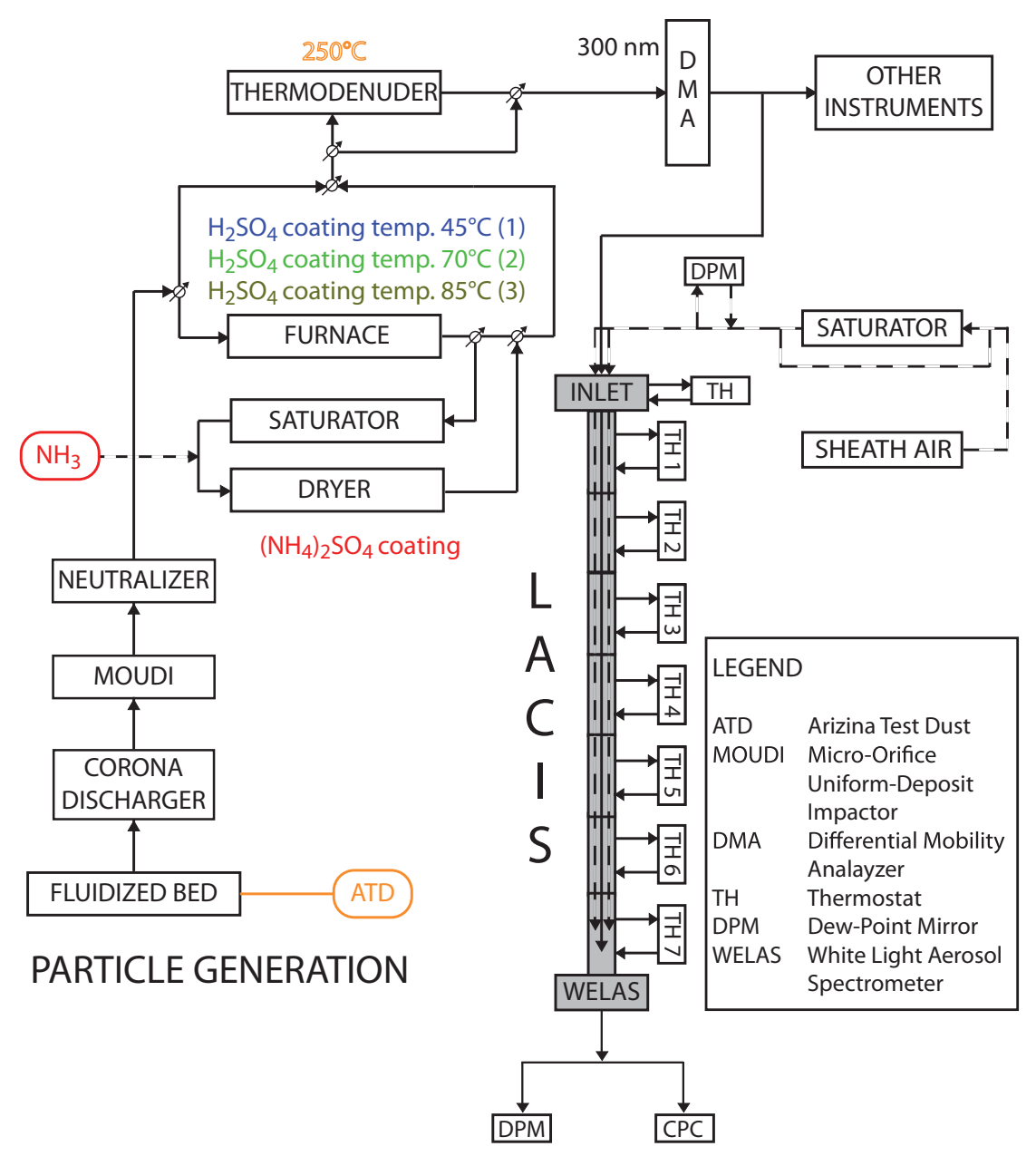

Fig. 1. Sketch of the generation, coating and size selection of the particles. Also included are the setup of particle conditioning and LACIS laminar flow tube. The "other instruments" box included CFDC, PINC, FINCH, ATOFMS, C-ToF-AMS, CCNC, H-TDMA and the CPC.

using a Humidity Tandem Differential Mobility Analyzer (H-TDMA, Research Center Jülich, Germany) and a Cloud Condensation Nucleus Counter (CCNC, DMT, Boulder, Colorado, USA, Roberts and Nenes, 2005), respectively. Finally four different ice nucleation instruments (the Portable Ice Nucleation Chamber (PINC, ETH Zurich, Zurich, Switzerland, Stetzer et al., 2008), the Fast Ice Nucleus CHamber counter (FINCH, University of Frankfurt, Frankfurt, Germany, Bundke et al., 2008), the Continuous Flow thermal gradient Diffusion Chamber (CFDC, Colorado State University, Fort Collins, Colorado, USA, Sullivan et al., 2010a) and LACIS) were used to investigate the IN ability of the particles in the immersion freezing, immersion/condensation freezing and deposition nucleation mode.

\subsection{LACIS-measurement procedure}

During FROST 2, the LACIS measurement procedure was similar to that applied in the course of the FROST 1 campaign (see Hartmann et al., 2011; Niedermeier et al., 2010). The aerosol flow entered LACIS (Fig. 1) with a dew-point temperature of about $-40^{\circ} \mathrm{C}$. A part of the particle free sheath air flow was humidified by a saturator (Perma Pure PH-30T-24KS, Perma Pure LLC, Toms River, New Jersey, USA) and subsequently mixed with the remaining dry air flow, resulting in dew-point temperatures between $-7.0^{\circ} \mathrm{C}$ and $-0.4^{\circ} \mathrm{C}$. The dew-point temperatures were monitored using a dew-point mirror (DPM, Dew Master, Edge Tech, Milford, Massachusetts, USA) measuring with an accuracy of $\pm 0.1 \mathrm{~K}$.

The dry aerosol and humidified sheath air flows were combined in the inlet section of LACIS with the aerosol flow being confined by the sheath air to a narrow beam of about $2 \mathrm{~mm}$ in diameter at the center axis of LACIS. The volume flow rates of sheath air and aerosol flow were chosen such 
that both flows entered LACIS in an isokinetic fashion with a velocity of about $0.4 \mathrm{~m} \mathrm{~s}^{-1}$. All experiments were performed at atmospheric pressure.

LACIS itself is a laminar flow tube with an inner diameter of $15 \mathrm{~mm}$ and a length of $7 \mathrm{~m}$. It is divided in seven $1 \mathrm{~m}$ tubes, each surrounded by a thermostated glysantin/water-mixture (thermostats 1 to 5: JULABO FP50, JULABO Labortechnik $\mathrm{GmbH}$, Seelbach, Germany) or ethanol jacket (thermostats 6 and 7: JULABO LH85) so that the temperature of each section can be controlled separately (Fig. 1).

For the detection of the particles at the outlet of LACIS, a white light aerosol spectrometer $\left(\mathrm{WELAS}^{\circledR} 1000\right.$ PALAS $^{\circledR}$, Karlsruhe, Germany) was used. Downstream of WELAS ${ }^{\circledR}$, the particle concentration was measured by means of a CPC (TSI 3010, TSI Inc., St. Paul, Minnesota, USA). The outlet dew-point temperature was monitored using another DPM (MBW 973, MBW Calibration Ltd., Wettingen, Switzerland) measuring with an accuracy of $\pm 0.05 \mathrm{~K}$.

The inlet temperature and the wall temperature of the first LACIS section were set to $20^{\circ} \mathrm{C}$. The wall temperatures of section 2 to 5 were set to $0^{\circ} \mathrm{C}$. The temperatures of sections 6 and 7, from here on called freezing sections, were set to identical values and varied between -28 and $-40{ }^{\circ} \mathrm{C}$ during the experiments. The inner tube walls of the freezing sections were coated with ice by setting the inlet dewpoint of the sheath air flow to about $-7{ }^{\circ} \mathrm{C}$ and cooling the freezing tubes down to $-40^{\circ} \mathrm{C}$ for $5 \mathrm{~min}$ prior to the measurements. This procedure ensured well-defined and reproducible wall boundary conditions for both the experiments themselves and the numerical simulations described in Hartmann et al. (2011).

The LACIS settings are chosen such that supercooled droplets are generated within section 6 and subsequently freeze due to further cooling. Supercooled droplets which do not freeze inside the freezing sections evaporate due to the Wegener-Bergeron-Findeisen effect (Findeisen, 1938), caused by both the ice coating the inner tube walls and the nucleated ice crystals. From model calculations (Hartmann et al., 2011) we know that the supercooled, unfrozen droplets evaporate within the second freezing section somewhere along the tube depending on the chosen inlet dewpoint and wall temperature. Consequently the residence time (i.e., the time interval during which the supercooled droplets can freeze) depends on these two parameters. During the experiments care was taken that regardless of the chosen wall temperature in the freezing sections, droplets always experienced similar residence times. This was achieved by adjusting the inlet dewpoint temperature according to the wall temperatures set in the freezing sections.

The advantage of this measurement setup is that only frozen droplets and seed particles remain, which can easily be distinguished with the WELAS ${ }^{\circledR}$ instrument by size, enabling the determination of ice fractions, i.e., the number of frozen droplets divided by the total particle number (Niedermeier et al., 2010).

\section{Results}

In the following we introduce abbreviations to make the different particle treatments clearly distinguishable. The untreated particles are labeled as: pure ATD. The sulfuric acid coatings at the three different temperatures are labeled as: $\operatorname{ATD}+\mathrm{SA}\left(45^{\circ} \mathrm{C}\right)$, $\mathrm{ATD}+\mathrm{SA}\left(70^{\circ} \mathrm{C}\right)$ and ATD $+\mathrm{SA}\left(85^{\circ} \mathrm{C}\right)$. The sulfuric acid coated and water bath exposed particles are labeled as: $\mathrm{ATD}+\mathrm{SA}\left(70^{\circ} \mathrm{C}\right)+\mathrm{WB}$; if ammonia gas was added as well, the label is: $\mathrm{ATD}+\mathrm{SA}\left(70^{\circ} \mathrm{C}\right)+\mathrm{WB}+\mathrm{NH}_{3}$. In case of the thermodenuder inclusion, the addition " $+\mathrm{TD}$ " is attached to the given coating treatment.

\subsection{Physical and chemical properties of the differently treated particles}

To get information about the shape and surface structure of the ATD particles we investigated pure ATD and ATD $+\mathrm{SA}\left(70^{\circ} \mathrm{C}\right)$ by transmission electron microscopy (TEM, Zeiss Libra 200FE) (Fig. 2). The TEM images show that more or less each particle is unique. The surface properties differ from particle to particle and on the particles themselves, clearly pointing out the heterogeneity of the particles and the particle surfaces. A clear difference between pure ATD and ATD $+\mathrm{SA}\left(70^{\circ} \mathrm{C}\right)$ is not apparent from these images. By electron diffraction in the TEM it becomes clear that the particles' surfaces feature both crystalline and amorphous structures.

Concerning chemical composition, the C-ToF-MS detected the fragments $\mathrm{HSO}_{3}^{+}$and $\mathrm{H}_{2} \mathrm{SO}_{4}^{+}$in different intensities for ATD $+\mathrm{SA}\left(45^{\circ} \mathrm{C}\right), \mathrm{ATD}+\mathrm{SA}\left(70^{\circ} \mathrm{C}\right)$ and $\mathrm{ATD}+$ $\mathrm{SA}\left(85^{\circ} \mathrm{C}\right)$, indicating that sulfuric acid as well as ammonium sulfate are present on the particles (Reitz et al., 2011). The presence of ammonium sulfate could be caused by impurities of ammonia in the compressed air which was used in the experiments. However, the uptake of ammonia onto sulfuric acid is very low under dry conditions (without additional wetting, the dewpoint temperature during our particle generation procedure is approximately $-40^{\circ} \mathrm{C}$ ). That implies that only a small fraction of the sulfuric acid coating should be neutralized without the water bath in line. The C-ToF-MS also detected the fragment $\mathrm{SO}_{3}^{+}$in intensities depending on the coating amount. This fragment can originate from ammonium sulfate and bisulfate salts but most presumably from metal sulfate salts.

Silicone was found by the C-ToF-AMS on the pure ATD particles. Reitz et al. (2011) suggest the compressed air as source for the silicone. However, test measurements performed during FROST 1, during which the AMS was directly fed from a shaken stainless steel vessel supplied with filtered ambient air, indicated silicone to be part of the dust itself. Furthermore, experiments performed using nitrogen instead of compressed air in the aerosol generation section gave similar freezing behavior of the coated and uncoated 


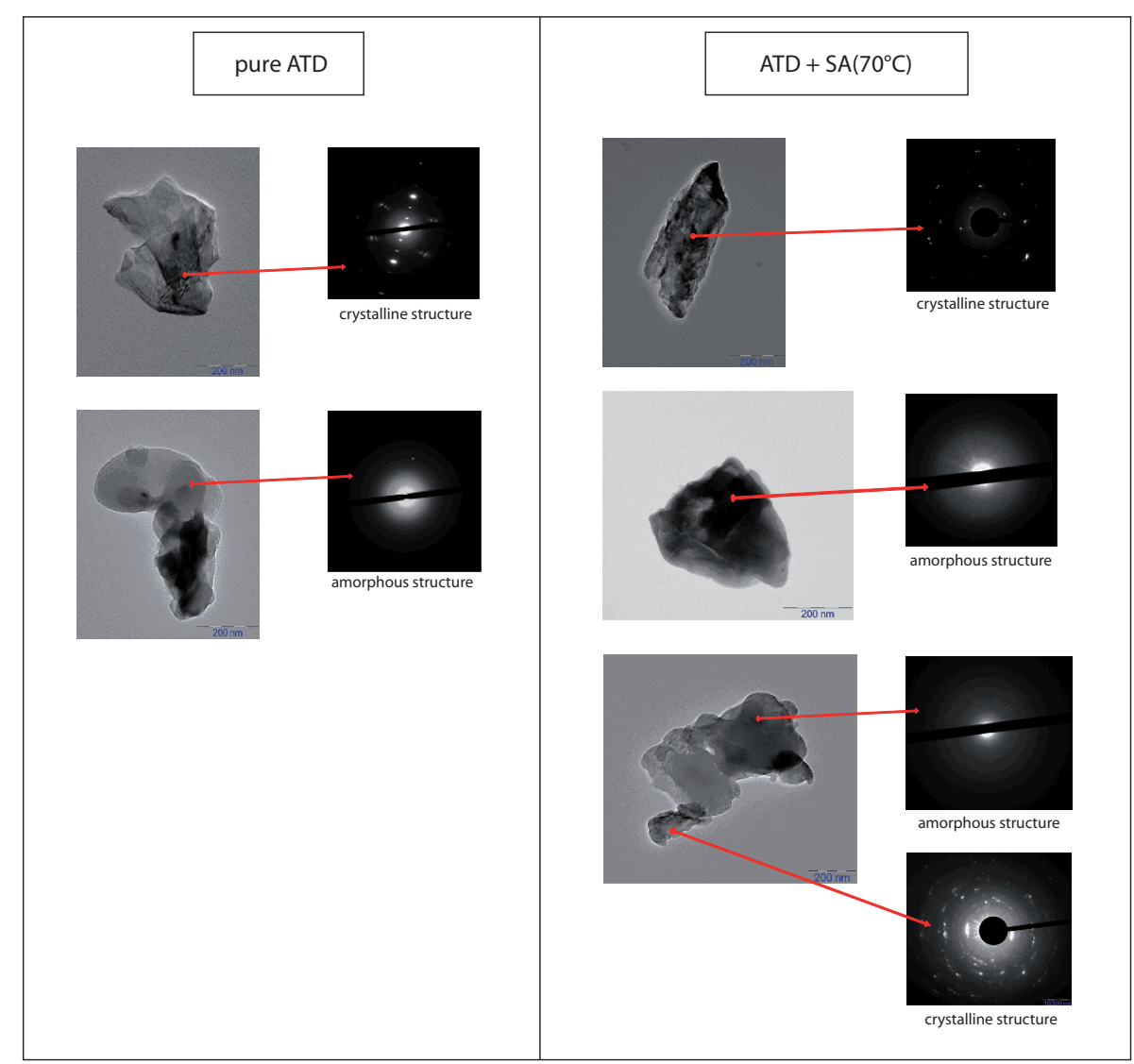

Fig. 2. Images resulting of Transmission Electron Microscopy (TEM) investigations for pure ATD (left panel) and ATD $+\mathrm{SA}\left(70{ }^{\circ} \mathrm{C}\right)($ right panel) are presented on the left of the panels. Additionally, results of electron diffraction are shown on the right of the panels where the red arrows indicated the investigated surface area.

dust particles. Besides silicon, also organic compounds were detected on the ATD particles (Reitz et al., 2011). Both the silicon and organic contaminations are likely due to the source and the production method for ATD. However, our experiments show that the small amounts of silicone or other organic contamination did not play a significant role in our measurements.

Assuming a spherical dust particle with a diameter of $300 \mathrm{~nm}$, the amount of sulfate to produce a complete monolayer on the particle surface is estimated to be 287 attograms per particle (ag particle ${ }^{-1}, 1 \mathrm{ag}=10^{-18} \mathrm{~g}$ ). The amount of sulfate condensed on ATD $+\mathrm{SA}\left(45^{\circ} \mathrm{C}\right)$ was found to be about $900 \mathrm{ag} \mathrm{particle}^{-1}$ (Reitz et al., 2011). For ATD + $\mathrm{SA}\left(70^{\circ} \mathrm{C}\right)$ and $\mathrm{ATD}+\mathrm{SA}\left(85^{\circ} \mathrm{C}\right)$ the derived sulfate mass was about $1850 \mathrm{ag}$ particle ${ }^{-1}$ and $3000 \mathrm{ag}$ particle ${ }^{-1}$, respectively. Consequently for all three coating temperatures sufficient sulfate mass was available to potentially cover/react with the complete particle surface (Reitz et al., 2011; Sullivan et al., 2010a).

For ATD $+\mathrm{SA}\left(70^{\circ} \mathrm{C}\right)+\mathrm{WB}+\mathrm{NH}_{3}$ and $\mathrm{ATD}+\mathrm{SA}\left(70^{\circ} \mathrm{C}\right)$ $+\mathrm{WB}$, the C-ToF-AMS measurements show that the coating amounts and ammonia signals in both experiments are com- parable (sulfate mass of about 2700 ag particle ${ }^{-1}$ to about $2600 \mathrm{ag}$ particle ${ }^{-1}$ ). Most of the sulfate/ammonia signals could be attributed to metal sulfates and possibly metal bisulfates or ammonium sulfate. The amount of metal sulfate salts was larger compared to experiments with sulfuric acid coatings under dry conditions. The missing difference between the experiments with and without ammonia addition could be caused by saturation effects due to the compressed air and/or the tubing downstream of the water bath being contaminated with ammonia, or the ammonia being unimportant in the occurring surface modifications. As will be shown in the discussion section, the latter is most likely the case, because the addition of water vapor leads to an increased reaction between sulfuric acid and particle surface, consuming the available sulfuric acid.

For the thermal treatment experiments using the thermodenuder operating at $250^{\circ} \mathrm{C}$, the C-ToF-AMS detected a clear decrease in the coating amounts for $\mathrm{ATD}+\mathrm{SA}\left(45^{\circ} \mathrm{C}\right)+\mathrm{TD}, \mathrm{ATD}+\mathrm{SA}\left(70^{\circ} \mathrm{C}\right)+\mathrm{TD}$ and $\mathrm{ATD}+\mathrm{SA}\left(85^{\circ} \mathrm{C}\right)+\mathrm{TD}$ compared to the experiments without additional thermal treatment. But some sulfate remained and the corresponding sulfate masses after thermal 

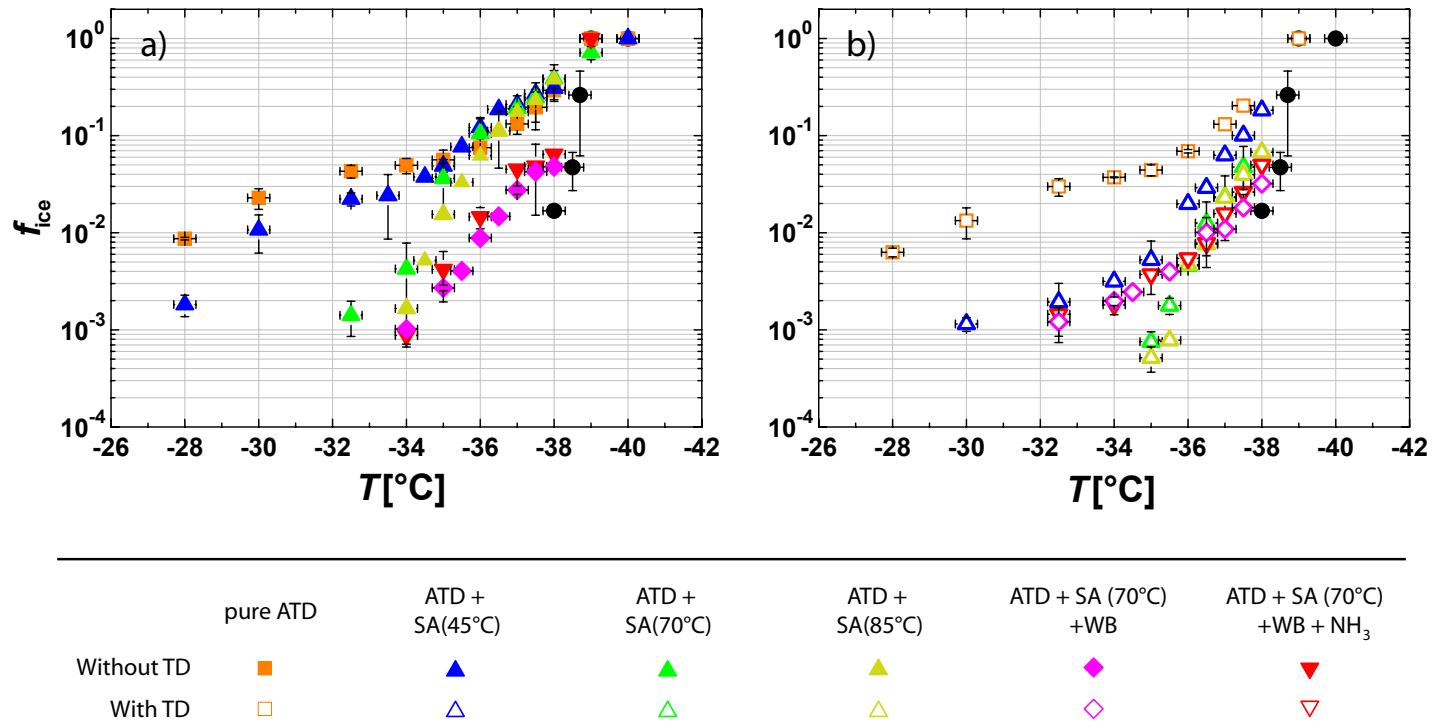

Fig. 3. Immersion freezing behavior of all types of examined particles. Panel (a) shows ice fractions $f_{\text {ice }}$ of pure and coated ATD particles (filled symbols). Panel (b) shows $f_{\text {ice }}$ of the thermally treated pure and coated ATD particles using a thermodenuder operating at $250{ }^{\circ} \mathrm{C}$ (open symbols). Different colors indicate different particle types/treatments: pure ATD (orange squares), ATD $+\mathrm{SA}\left(45^{\circ} \mathrm{C}\right)(\mathrm{blue}$ triangles), $\mathrm{ATD}+\mathrm{SA}\left(70^{\circ} \mathrm{C}\right)$ (green triangles), $\mathrm{ATD}+\mathrm{SA}\left(85^{\circ} \mathrm{C}\right)$ (dark yellow triangles), $\mathrm{ATD}+\mathrm{SA}\left(70^{\circ} \mathrm{C}\right)+\mathrm{WB}($ pink diamonds) and $\mathrm{ATD}+\mathrm{SA}\left(70^{\circ} \mathrm{C}\right)+\mathrm{WB}+\mathrm{NH}_{3}$ (upside down red triangles). Additionally, results for homogeneous freezing of highly diluted ammonium sulfate droplets are shown (black dots).

treatment are about $500 \mathrm{ag}$ particle ${ }^{-1}$ for ATD $+\mathrm{SA}\left(45^{\circ} \mathrm{C}\right)$ $+\mathrm{TD}, \quad 1050 \mathrm{ag}$ particle ${ }^{-1}$ for $\mathrm{ATD}+\mathrm{SA}\left(70^{\circ} \mathrm{C}\right)+\mathrm{TD}$ and $1250 \mathrm{ag}$ particle ${ }^{-1}$ for $\mathrm{ATD}+\mathrm{SA}\left(85^{\circ} \mathrm{C}\right)+\mathrm{TD}$. When the particles had been additionally exposed to water vapor, the thermal treatment only lead to a slight reduction of the coating mass (sulfate masses after thermal treatment of about $2550 \mathrm{ag}$ particle ${ }^{-1}$ for $\mathrm{ATD}+\mathrm{SA}\left(70^{\circ} \mathrm{C}\right)+\mathrm{WB}+\mathrm{NH}_{3}+\mathrm{TD}$ and about 2500 ag particle $\left.{ }^{-1} \mathrm{ATD}+\mathrm{SA}\left(70^{\circ} \mathrm{C}\right)+\mathrm{WB}+\mathrm{TD}\right)$, suggesting that the sulfate salts formed in the presence of water vapor were not volatile at $250^{\circ} \mathrm{C}$.

\subsection{LACIS immersion freezing results}

The ice fractions $f_{\text {ice }}$ as measured with LACIS in the immersion freezing mode for the differently treated ATD particles are presented in Figs. 3 and 4 for given wall temperatures in the freezing sections. It should be noted that the wall temperature is equal to the freezing temperature as described in Niedermeier et al. (2010). Additionally, the results for homogeneous freezing of highly diluted ammonium sulfate solution droplets are shown. It is clearly visible that homogeneous freezing is the dominating ice nucleation process for $T<-38^{\circ} \mathrm{C}$. For higher temperatures ice formation occurs through immersion freezing as discussed in Niedermeier et al. (2010). These findings are also supported by the numerical simulations presented in Hartmann et al. (2011).

For all particle types, $f_{\text {ice }}$ increases with decreasing temperature, but in different manners (Fig. 3). Results from the FROST 1 campaign demonstrated already that a freezing point suppression due to dissolved coating material, as observed by e.g., Hung et al. (2003) and Zobrist et al. (2008), cannot cause the differences in the determined ice fractions. For the investigated temperature range the droplets inside LACIS are activated and reach diameters larger than $1 \mu \mathrm{m}$ before freezing occurs. Considering the coating amounts, the water activity of the supercooled droplets is approximately 1 , i.e., the solution droplets are highly diluted when freezing occurs. Therefore only varying surface properties caused by the particle treatments can lead to the different IN efficiencies (Niedermeier et al., 2010).

Pure ATD nucleated ice over the whole temperature range investigated. Two different freezing branches exist, i.e. there are two different freezing temperature dependencies visible in the ice fraction curves, characterized by different slopes with a "knee" at about $-35^{\circ} \mathrm{C}$ (Fig. 4a). This behavior was not observable during the FROST 1 campaign because there the highest freezing temperature investigated was $-34^{\circ} \mathrm{C}$.

Coating the particles with sulfuric acid at $45^{\circ} \mathrm{C}$ $\left(\mathrm{ATD}+\mathrm{SA}\left(45^{\circ} \mathrm{C}\right)\right)$ decreased $f_{\text {ice }}$ slightly for the first, high temperature freezing branch (i.e., $T>-35^{\circ} \mathrm{C}$ ). For ATD + $\mathrm{SA}\left(70^{\circ} \mathrm{C}\right)$ and $\mathrm{ATD}+\mathrm{SA}\left(85^{\circ} \mathrm{C}\right), f_{\text {ice }}$ was below the quantification limit of about $5 \times 10^{-4}$ for the first freezing branch (Fig. $4 \mathrm{~d}$ and f). In contrast, in the second, low temperature freezing branch $\left(T \leq-35^{\circ} \mathrm{C}\right), f_{\text {ice }}$ was slightly increased by all of the sulfuric acid coatings (by a factor of 1.5 in maximum), with the effect becoming less pronounced with increasing coating temperature. Although the effect is close 

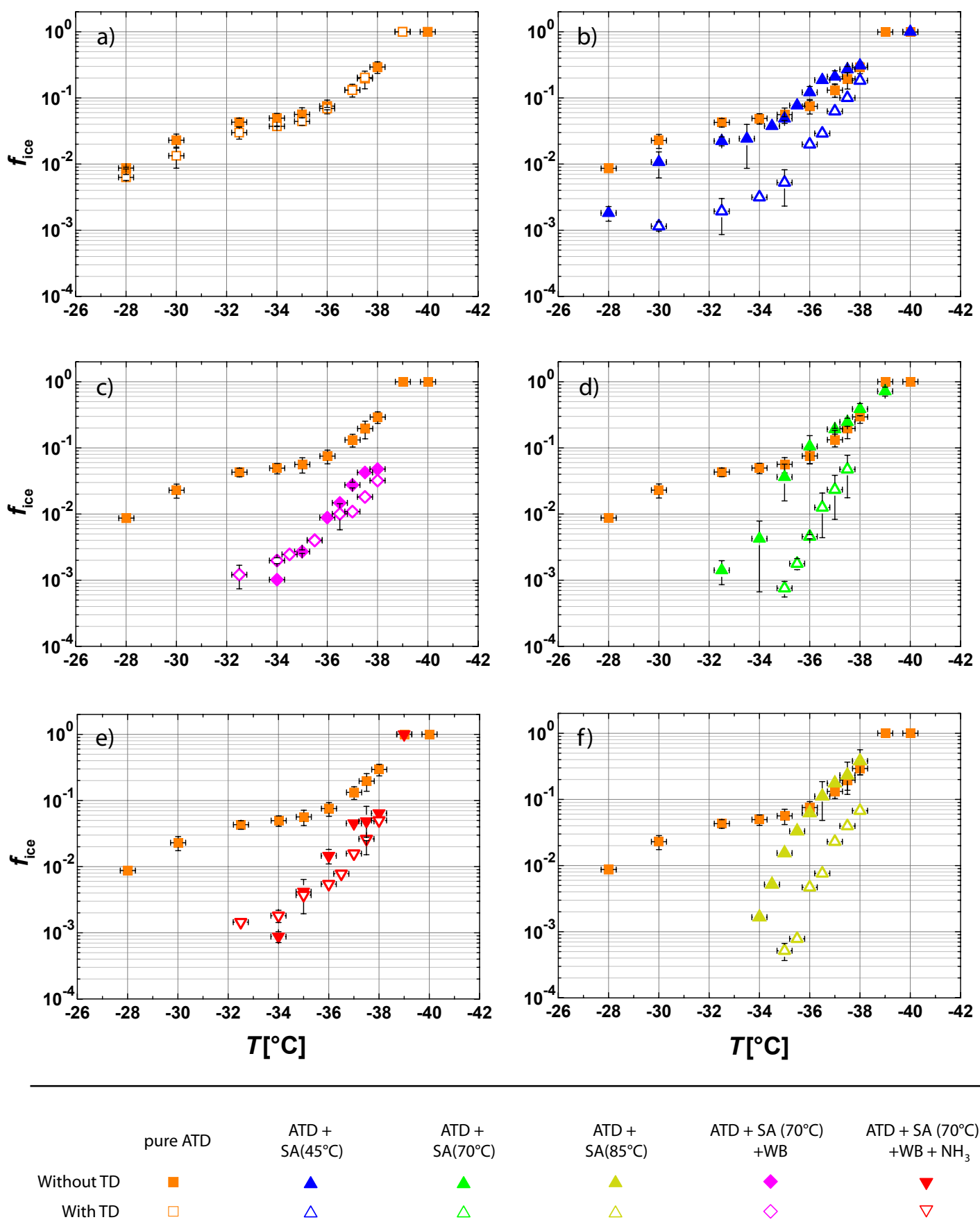

Fig. 4. Immersion freezing behavior of all types of examined particles. (a) pure ATD (orange squares), (b) ATD $+\mathrm{SA}\left(45^{\circ} \mathrm{C}\right)$ (blue triangles), (c) ATD $+\mathrm{SA}\left(70^{\circ} \mathrm{C}\right)+\mathrm{WB}$ (pink diamonds), (d) $\mathrm{ATD}+\mathrm{SA}\left(70^{\circ} \mathrm{C}\right)$ (green triangles), (e) $\mathrm{ATD}+\mathrm{SA}\left(70{ }^{\circ} \mathrm{C}\right)+$ $\mathrm{WB}+\mathrm{NH}_{3}$ (upside down red triangles) and panel (f) $\mathrm{ATD}+\mathrm{SA}\left(85^{\circ} \mathrm{C}\right)$ (dark yellow triangles). Open and filled symbols represent particles that were and were not thermally treated, respectively. For comparison the ice fractions for pure ATD are inserted in each panel.

and partly within the experimental uncertainty, it is worth mentioning, as it suggests an increase of the ATD's IN potential in the temperature range below $-35^{\circ} \mathrm{C}$ due to the sulfuric acid coating.
For the treatments $\mathrm{ATD}+\mathrm{SA}\left(70^{\circ} \mathrm{C}\right)+\mathrm{WB}$ and $\mathrm{ATD}+\mathrm{SA}\left(70^{\circ} \mathrm{C}\right)+\mathrm{WB}+\mathrm{NH}_{3}, \quad f_{\text {ice }}$ decreased about one order of magnitude in the whole temperature range investigated compared to pure and sulfuric acid coated particles. Regardless of whether ammonia gas was added or not, the IN ability was identical for both treatments (Fig. 4c 
and e). A detailed discussion concerning this nonexisting difference in the IN ability is given in the discussion section.

Figure $3 \mathrm{~b}$ as well as Fig. 4 show $f_{\text {ice }}$ of the pure and coated particles that had been additionally thermally treated by means of the thermodenuder which was operated at $250{ }^{\circ} \mathrm{C}$. $f_{\text {ice }}$ of pure ATD + TD did not change within the error bars compared to the pure ATD case (Fig. 4a). In contrast, $f_{\text {ice }}$ of the sulfuric acid coated particles clearly decreased about one order of magnitude for all three coating conditions. The higher the sulfuric acid coating amount prior to thermal treatment the lower was the IN ability afterwards. In case of $\mathrm{ATD}+\mathrm{SA}\left(70^{\circ} \mathrm{C}\right)+\mathrm{WB}$ and $\mathrm{ATD}+\mathrm{SA}\left(70^{\circ} \mathrm{C}\right)+\mathrm{WB}+\mathrm{NH}_{3}$ the thermodenuder did not cause a significant change of $f_{\text {ice }}$ compared to measurements without the thermodenuder. Only the slope of the ice fraction changed such that after thermal treatment $f_{\text {ice }}$ was slightly lower for $T<-35^{\circ} \mathrm{C}$ and slightly higher for $T>-35^{\circ} \mathrm{C}$ compared to the thermally untreated particles. However, the differences are well within the measurement uncertainties.

\subsection{Comparison between CFDC and LACIS data}

Although measurement techniques and detection methods differ between CFDC (Sullivan et al., 2010a) and LACIS, a comparison of the ice fractions measured with both instruments is presented in Fig. 5 for $T=-30^{\circ} \mathrm{C}$. With LACIS the only freezing process occurring was immersion freezing. With the CFDC the freezing behavior of the particles at a final relative humidity of about $105 \%$ with respect to liquid water was investigated. A combination of ice nucleation processes could occur when the particles reach this RH-value, but condensation and immersion freezing were expected to be predominant (Sullivan et al., 2010a). Elevated fractions of particles freezing at $105 \% \mathrm{RH}$ in comparison to the deposition regime occur in coincidence with activation of droplets on dust that grow to sizes quite similar to those cooled in LACIS on the basis of the model of Rogers (1988).

Similar trends in the ice nucleating ability of the particles with different treatments were observed. For pure ATD, pure $\mathrm{ATD}+\mathrm{TD}, \mathrm{ATD}+\mathrm{SA}\left(45^{\circ} \mathrm{C}\right)$ and $\mathrm{ATD}+\mathrm{SA}\left(45^{\circ} \mathrm{C}\right)+\mathrm{TD}$, the ice fractions determined with the CFDC and LACIS agree to within a factor of two and in all but one case the measurements are within the experimental uncertainties. For the other treatments namely ATD $+\mathrm{SA}\left(70^{\circ} \mathrm{C}\right)$, ATD + $\mathrm{SA}\left(70^{\circ} \mathrm{C}\right)+\mathrm{TD}, \mathrm{ATD}+\mathrm{SA}\left(85^{\circ} \mathrm{C}\right)$ and $\mathrm{ATD}+\mathrm{SA}\left(85^{\circ} \mathrm{C}\right)$ $+\mathrm{TD}$ as well as ATD $+\mathrm{SA}\left(70^{\circ} \mathrm{C}\right)+\mathrm{WB}+\mathrm{NH}_{3}$ and ATD $+\mathrm{SA}\left(70^{\circ} \mathrm{C}\right)+\mathrm{WB}+\mathrm{NH}_{3}+\mathrm{TD}$, ice crystal formation was observed with LACIS but the number of detected ice crystals was too small at $-30^{\circ} \mathrm{C}$ to determine reliable ice fraction (ice fractions were below the quantification limit of about $5 \times 10^{-4}$ ). Ice fractions measured with the CFDC for these cases were partly above the LACIS detection limit however with the error bars including values well below that limit. In summary, for the temperature where data is available from both instruments, i.e. $T=-30^{\circ} \mathrm{C}$, the agreement for pure

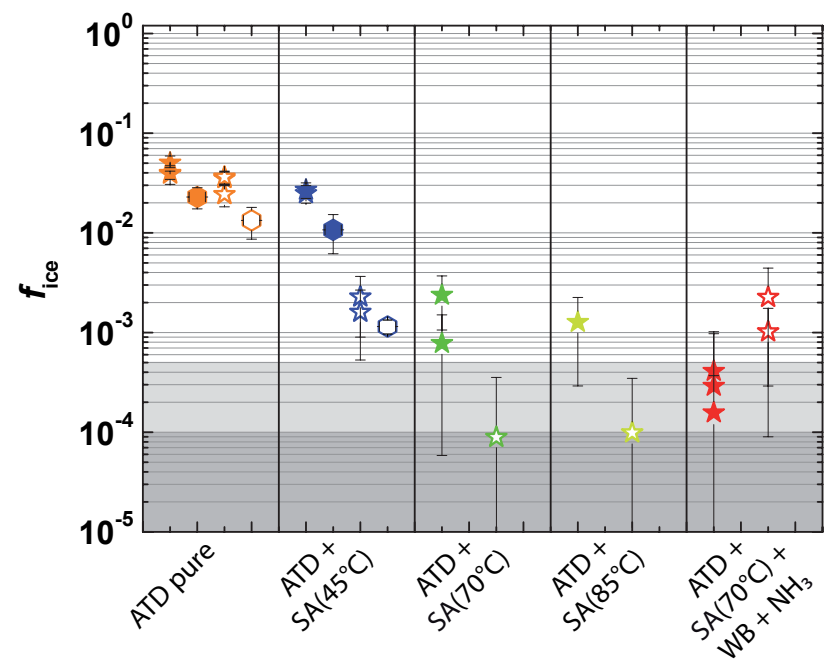

Fig. 5. Comparison between CFDC condensation/immersion freezing data (stars) and LACIS immersion freezing results (hexagons) at $T=-30{ }^{\circ} \mathrm{C}$. Measurements without thermodenuder are shown by filled symbols while measurements with thermodenuder are presented as open symbols. The quantification limits of LACIS and CFDC are marked by the light grey and dark grey area, respectively. Where no data from LACIS is given, measured $f_{\text {ice }}$ was below the quantification limit.

ATD $(+$ TD $)$ and ATD $+\mathrm{SA}\left(45^{\circ} \mathrm{C}\right)(+\mathrm{TD})$ and the similar trends we saw in general between the CFDC and LACIS data are encouraging.

\section{Discussion}

As already shown in Fig. 2, the particle surfaces feature crystalline and amorphous structures, i.e., there is a variability in the surface properties across the population of ATD particles. Considering these findings together with those of Niedermeier et al. (2011), it is plausible that the particles posses surface sites/structures with different energy barriers which have to be overcome to initiate ice nucleation. For example crystalline surface structures with hexagonal or pseudohexagonal arrangement of hydroxyl groups at the surface of the lattice may exhibit a higher nucleation potential than amorphous structures ${ }^{1}$ (Pruppacher and Klett, 1997). Hu and Michaelides (2007) showed, however, by means of a series of density-functional theory calculations for the adsorption of water on the hydroxylated and siloxane surfaces of kaolinite that the stability of an ice layer formed on the kaolinite surface is not due to the favorable lattice match with ice. Instead it is caused by the substrate being amphoteric with the ability

\footnotetext{
${ }^{1}$ Not implying that amorphous particles do not initiate ice nucleation in general. E.g., Murray et al. (2010) found that glassy (amorphous, non-crystalline) particles initiated ice nucleation under cirrus conditions.
} 
to accept and donate $\mathrm{H}$ bonds. Additionally, surface dislocations like steps, etch pits, edges, etc. could enhance the ice nucleation process. This is relevant because surface features with the lowest energy barrier have the highest probability to initiate ice nucleation at a given temperature.

For pure ATD particles it was found that two different freezing branches exist which are characterized by different slopes in the ice fraction versus temperature curves (see Fig. 4). This freezing behavior cannot be explained by doubly charged, i.e. larger particles because the $\mathrm{CCNC}$ measurements indicate that droplet activation took place in a small supersaturation interval without exhibiting any steps (Wex et al., 2011). That means the number of doubly charged particles was negligible during the experiments. This freezing behavior more likely suggests that within the population of ATD particles, only a small number of particles exhibits surface features with comparatively high nucleation potentials (see small ice fraction values within the first freezing branch, $T>-35^{\circ} \mathrm{C}$ ). However, the majority of particles exhibit surface features with lower nucleation potential (inducing freezing at temperatures below $-35^{\circ} \mathrm{C}$ ). It is conceivable that the applied particle treatments affect these different surface features and their ice nucleation abilities in different ways, and indeed such a behavior was observed.

Before going into more detail, and to avoid confusion, we first would like to address the issue of inhomogeneous or incomplete coating of the ATD particles. Reitz et al. (2011) stated that the ATOFMS data show that 93 to $100 \%$ of the sulfuric acid coated particles contained sulfate (applying the less conservative threshold based on the signal quality of the individual mass spectra). However, sulfate peaks were also detected for pure ATD particles making the quantification of sulfate compounds on the particles somewhat ambiguous. The fraction of pure ATD particles that showed a sulfate peak ranges from 5 to $46 \%$, again based on the less conservative threshold. The missing sulfate peak for a small fraction of sulfuric acid coated particles in the ATOFMS is presumably related to very low amounts of sulfate on the particle surface so that no significant signal in the ATOFMS was produced, despite the presence of sulfate. Furthermore, CCNC measurements show that droplet activation took place in a small supersaturation interval without exhibiting any steps indicating that the aerosol was not externally mixed (Wex et al., 2011). Therefore it is more likely that for ATD $+\mathrm{SA}\left(45^{\circ} \mathrm{C}\right)$ each particle contained at least some coating material but its distribution over the particle surface may not have been homogeneous. Such inhomogeneous sulfuric acid coatings on ATD particles were also found by Cziczo et al. (2009) based on single-particle mass spectrometry measurements. This might explain the comparably small changes in IN ability for the ATD $+\mathrm{SA}\left(45^{\circ} \mathrm{C}\right)$ case under dry conditions. However, for the other coating temperatures there are strong indications towards a complete coating. Therefore, from here on our discussion will mainly rely on the data for pure ATD particles or ATD $+\mathrm{SA}\left(70^{\circ} \mathrm{C}\right)$ and $\mathrm{ATD}+\mathrm{SA}\left(85^{\circ} \mathrm{C}\right)$.
Referring to the results obtained for dry conditions, i.e. $\mathrm{ATD}+\mathrm{SA}\left(70^{\circ} \mathrm{C}\right)$ and $\mathrm{ATD}+\mathrm{SA}\left(85^{\circ} \mathrm{C}\right), f_{\text {ice }}$ was significantly reduced within the first freezing branch but slightly increased within the second branch $\left(T \leq-35^{\circ} \mathrm{C}\right)$. We suggest that the "effective" surface features (i.e., sites with comparatively high nucleation potential) are destroyed or changed easily by the sulfuric acid coating leading to the disappearance of the first freezing branch with increasing coating amount. The small increase of $f_{\text {ice }}$ in the second freezing branch is suggestive for substances or surface features being formed which exhibit higher nucleation potential and consequently increase the IN ability. This is an interesting observation in itself, similar to observations made for sulfuric acid coating on iron oxide (hematite) particles (Archuleta et al., 2005), and needs further investigation. Application of the thermodenuder interestingly led to a significant reduction of the IN ability, with the second branch being affected as well. This is a strong indication that the substances and/or surface features nucleating ice in the second branch are destroyed by the additional thermal treatment (the effect of the thermal treatment will be discussed in more detail later). In general, reactions forming e.g. calcium sulfate $\left(\mathrm{CaSO}_{4}\right)$, magnesium sulfate $\left(\mathrm{MgSO}_{4}\right)$ as well as reactions between sulfuric acid and aluminosilicates are possible under dry conditions. However, we cannot distinguish whether certain chemical components or surface features are destroyed by the sulfuric acid. Most likely both processes are taking place. Nevertheless, assuming chemical reactions to be responsible for the reduction of the IN potential, from the observed reaction products (the metal sulfates) one could speculate, that the precursors of these reaction products, i.e. the aluminosilicates, could be responsible for the ice nucleation. This finding would be in line with e.g., Mason (1960), Kanji et al. (2008) and Murray et al. (2011), who indicated that aluminosilicates, which are major components of kaolinite, montmorillonite and other clay minerals, contribute to the ice nucleation potential. However, further experiments are needed to explore and explain the differences in the ice nucleation behavior of the two freezing branches and to quantify the relative importance of chemical reactions versus destruction or creation of ice nucleating surface features.

For the $\mathrm{ATD}+\mathrm{SA}\left(70^{\circ} \mathrm{C}\right)+\mathrm{WB}+\mathrm{NH}_{3}$ and $\mathrm{ATD}+\mathrm{SA}\left(70^{\circ} \mathrm{C}\right)+\mathrm{WB}$ treatments, the surface modifications seem to have a greater influence since the IN ability is decreased strongly for both freezing branches. Due to the addition of water vapor and ammonia, two competitive reactions could take place. On the one hand the neutralization of the sulfuric acid could occur forming ammonium sulfate on the particle surface. On the other hand an enhanced reaction of the sulfuric acid with substances in/on the particle surface is plausible due to the addition of water vapor. The question is which of these reactions is fastest and leads to this strong IN ability reduction. The C-ToF-AMS measurements showed that the neutralization of a part of the sulfuric acid occurred and that the humidification also 
caused increased surface reactions (Reitz et al., 2011), i.e., both reactions occurred simultaneously. Since ammonium sulfate is a soluble substance, it should dissolve completely as soon as the particles become activated to cloud droplets inside the LACIS tube. Thus, if the neutralization due to the ammonia was the dominating reaction, the resulting ammonium sulfate would most likely dissolve as soon as the particle becomes activated to a cloud droplet inside LACIS. Consequently, the particle surface would then exhibit conditions leading to an IN ability between the pure ATD and the ATD $+\operatorname{SA}\left(70^{\circ} \mathrm{C}\right)$ case. But this is not the case. Therefore it is more likely that the increased reaction of sulfuric acid with the particle surface dominates the IN ability reduction. This is in agreement with Lasaga (1995), who observed that the exposure to water vapor accelerates the reaction of sulfuric acid with mineral dust and indeed in the water vapor experiments a higher fraction of metal sulfate salts was formed compared to the sulfuric acid treatments without water vapor exposure.

Cwiertny et al. (2008) showed that iron which is predominantly substituted into aluminosilicate minerals of ATD becomes dissolved due to sulfuric acid and the presence of water $(\mathrm{pH}=1)$ forming (soluble) iron(II) and iron(III) sulfate $\left(\mathrm{FeSO}_{4}\right.$ and $\left.\mathrm{Fe}_{2}\left(\mathrm{SO}_{4}\right)_{3}\right)$. For our coating procedure we can estimate the $\mathrm{pH}$ value to range between 0 and 1 , using the hygroscopic growth measurements together with the amount of sulfate determined by the C-ToF-AMS for estimation. Consequently, the formation of iron sulfate is conceivable. The C-ToF-AMS and the CCNC data further indicate an increased formation of other soluble but refractory substances like aluminum sulfate $\left(\mathrm{Al}_{2}\left(\mathrm{SO}_{4}\right)_{3}\right), \mathrm{CaSO}_{4}$ or $\mathrm{MgSO}_{4}$ as well as ammonium metal sulfate salts (Reitz et al., 2011). This list of reaction products may not be complete as many other compounds could be present on the ATD surface. But in any case it is clear that changes in the INs' chemical composition as well as physical surface properties due to coating with sulfuric acid are enhanced if water vapor is present, leading to a more pronounced reduction in the ice nucleating efficiency. In other words, the presence of water vapor is responsible for the enhanced reaction between sulfuric acid and particle surface and consequently for the large reduction in IN ability. The formation of ammonium sulfate due to the addition of ammonia (intended or unintended) has a negligible influence on the particles' IN ability in the immersion freezing mode.

It should be noted that the increasing amount of sulfuric acid available for surface modification is coupled with an increased oven temperature, so we can not clearly separate the effects of coating amount and heat. But we can deduce that the higher temperature in the thermodenuder as well as the humidification after coating with sulfuric acid has a stronger effect on the IN ability than the influence of even the warmest oven temperature used to produce the coating $\left(85^{\circ} \mathrm{C}\right)$.

During the thermodenuder treatments, the IN were exposed to a temperature of $250^{\circ} \mathrm{C}$. This resulted in signifi- cant alterations of the particles' IN ability with the exception of the pure ATD + TD case, where the exposure to heat did not change the IN ability compared to pure ATD. This indicates that heating alone did not cause changes of the surface structure and composition. In contrast, the IN ability of the ATD $+\mathrm{SA}\left(45^{\circ} \mathrm{C}\right)+\mathrm{TD}, \mathrm{ATD}+\mathrm{SA}\left(70^{\circ} \mathrm{C}\right)+\mathrm{TD}$ and $\mathrm{ATD}+\mathrm{SA}\left(85^{\circ} \mathrm{C}\right)+\mathrm{TD}$ cases decreased strongly, compared to the respective cases where particles did not pass through the thermodenuder. No recovery of ice nucleation ability could be observed. In cases of ATD $+\mathrm{SA}\left(70^{\circ} \mathrm{C}\right)+\mathrm{TD}$ and $\mathrm{ATD}+\mathrm{SA}\left(85^{\circ} \mathrm{C}\right)+\mathrm{TD}$ the heat treatment resulted in the lowest IN abilities observed in the course of the experiments. Application of the thermodenuder in particular led (a) to the evaporation of a part of volatile material and (b) an enhanced reaction between sulfuric acid and particle surface following an Arrhenius-like relation, forming a higher amount of metal sulfate salts. Furthermore we think that the exposure to heat in the thermodenuder opened reaction channels producing more or other surface substances compared to the water vapor exposure experiments. It is likely that rigorous heating to $250^{\circ} \mathrm{C}$ directly after coating could lead to other reaction products than the water treatment after coating.

Regarding the experiments including water vapor exposure and thermodenuder, we found that the exposure to water vapor after sulfuric acid coating already changed surface properties uniformly and irreversibly by forming a high amount of soluble metal sulfate salts e.g., $\mathrm{Al}_{2}\left(\mathrm{SO}_{4}\right)_{3}, \mathrm{FeSO}_{4}$, $\mathrm{Fe}_{2}\left(\mathrm{SO}_{4}\right)_{3}$, etc. with decomposition temperatures higher than $250^{\circ} \mathrm{C}$. Consequently, the exposure to heat after the water bath could cause only minor effects (e.g. due the decomposition of ammonium metal sulfate compounds and further reaction of the products), and hence the IN ability was not reduced further due to the heating in the thermodenuder. In order to verify this explanation, further experiments are needed, which can unambiguously identify the substances produced on the ATD surface.

To summarize, we infer from C-ToF-AMS and ice nucleation measurements that the thermal treatment in the thermodenuder and the exposure to water vapor accelerated the reaction between sulfuric acid coating and mineral dust surface. But reaction channels and reaction products could differ between these two different treatments. In contrast, for the dry conditions the sulfuric acid coating only seemed to easily impair the ice nucleating ability of the highly ice active surface features. Since the IN ability was slightly increased in the second freezing branch due to the coating, ice nucleating substances and/or surface features which display higher ice nucleation potential might have formed. In general, the different surface treatments applied in the course of our investigations mainly resulted in a decrease of the ATD particles' IN potential leading to steeper freezing curves which were shifted towards the homogeneous freezing case. 


\section{Conclusions}

During the measurement campaign FROST 2 the ability of Arizona Test Dust particles to act as IN in the immersion freezing mode was investigated at LACIS. The particles were exposed to various thermochemical treatments including exposure to sulfuric acid at three different temperatures, to water vapor after sulfuric acid exposure with and without the addition of ammonia gas, and to heat using a thermodenuder operating at $250^{\circ} \mathrm{C}$. Thus, the influence of various surface modifications on the IN ability due to physicochemical reactions of coating material and particle surface was investigated.

First of all, it was found that two different freezing branches exist for pure ATD particles which are characterized by different slopes in the ice fraction versus temperature curves with a "knee" at $-35^{\circ} \mathrm{C}$. This freezing behavior emphasized the variability of the surface properties across the population of ATD particles where only a small number of particles exhibit surface features with comparatively low energy barriers, i.e., high nucleation potential. The sulfuric acid coating seemed to easily attack these highly ice active surface features so that with increasing coating amount the ice fraction within the first freezing branch $\left(T>-35^{\circ} \mathrm{C}\right)$ went below the quantification limit (about $5 \times 10^{-4}$ ). The IN ability in the second freezing branch was slightly increased suggesting that, due to the coating, ice nucleating substances and/or surface features might form which feature higher ice nucleation potential.

The addition of water vapor subsequent to the sulfuric acid coating induced highly effective surface modifications, most likely due to accelerated chemical reactions on the particle surface, significantly decreasing the IN ability in both freezing branches. Assuming chemical reactions to be responsible for the reduction in the IN potential, from the observed reaction products (sulfates, which are likely from metals), one could speculate that the precursors of these reaction products, i.e. the aluminosilicates, where iron and magnesium ions are predominantly included, could be inducing the ice nucleation. Sullivan et al. (2010b) also concluded from investigations concerning the deposition nucleation and immersion freezing behavior of ATD particles coated with nitric acid that aluminosilicate mineral phases may compose the most efficient ice nucleating features in ATD. The presence of ammonia gas after water vapor exposure led to neutralization of the remaining free sulfuric acid and has a negligible effect on the IN ability of the particles. In other words, the combination of both sulfuric acid and water vapor being present is the main cause for the ice active surface features of the ATD particles being destroyed. The exposure to ammonia after the water vapor exposure seems to be of secondary importance.

Thermal treatment of the pure dust particles did not alter their IN ability, indicating that heat alone does not change the surface structure and/or composition of the pure ATD particles. Significant reduction in IN ability was observed for sul- furic acid coated ATD particles that were passed through the thermodenuder, similar to the IN ability reduction for the sulfuric acid plus water vapor treated ATD particles. Although this rigorous heating to $250^{\circ} \mathrm{C}$ subsequent to the sulfuric acid coating, might lead to other reaction products compared to those from the exposure to water vapor, both treatments (water vapor and heat) enhanced the reaction between the sulfuric acid coating and the mineral dust. No recovery of the IN ability was observed indicating the irreversible destruction of the IN potential of the ATD particles due to the sulfuric acid coating. For the humidified sulfuric acid coated particles, the IN ability was only slightly changed after thermal treatment. In other words, the exposure to water vapor already irreversibly changed particle surface properties such that further heating in the thermodenuder caused no significant effects.

Finally, it is evident that the various particle treatments physicochemically and irreversibly altered the ATD particles' surfaces. The atmospheric relevance of this work is most directly related to the influence of atmospheric aging on the IN ability of dust particles. The strongly enhanced reaction between sulfuric acid and dust in the presence of water vapor, and the resulting reductions in IN effectiveness suggest that atmospheric IN concentrations could be significantly reduced upon aging (up to one order of magnitude for the conditions investigated here). Further investigations into the basic mechanisms for modifications in IN effectiveness are needed in order to fully appreciate the extent and magnitude of the atmospheric effects.

Acknowledgements. This work is part of a DFG project under contract HE 939/21-1 and the Russian Foundation for Basic Research (grant 10-03-00950-a). The measurement campaign FROST 2 was conducted within the Helmholtz Virtual Institute "Aerosol-Cloud Interactions" funded by the Helmholtz society. R. C. Sullivan and P. J. DeMott acknowledge additional support for US National Science Foundation grant ATM-0841602. Additionally, the campaign was financially supported by the research project EUROCHAMP funded within the EC 6th Framework Program, Section "Support for Research Infrastructures - Integrated Infrastructure Initiative". We would also like to thank J. Curtius, University of Frankfurt, for a valuable discussion, and the Interdisciplinary Resource Center for Nanotechnology of St. Petersburg State University and E. Ubyivovk for TEM analysis of the ATD samples.

Edited by: D. J. Cziczo

\section{References}

Ansmann, A., Tesche, M., Althausen, D., Müller, D., Seifert, P., Freudenthaler, V., Heese, B., Wiegner, M., Pisani, G., Knippertz, P., and Dubovik, O.: Influence of Saharan dust on cloud glaciationin Southern Morocco during the Saharan Mineral Dust Experiment, J. Geophys. Res., 113, D04210, doi:10.1029/2007JD008785, 2008. 
Archuleta, C. M., DeMott, P. J., and Kreidenweis, S. M.: Ice nucleation by surrogates for atmospheric mineral dust and mineral dust/sulfate particles at cirrus temperatures, Atmos. Chem. Phys., 5, 2617-2634, doi:10.5194/acp-5-2617-2005, 2005.

de Boer, G., Morrison, H., Shupe, M. D., and Hildner, R.: Evidence of liquid dependent ice nucleation in high-latitude stratiform clouds from surface remote sensors, Geophys. Res. Lett., 38, L01803, doi:10.1029/2010GL046016, 2011.

Broadley, S. L., Murray, B. J., Herbert, R. J., Atkinson, J. D., Dobbie, S., Condliffe, E., and Neve, L.: Immersion mode heterogeneous ice nucleation by an illite rich powder representative of atmospheric mineral dust, Atmos. Chem. Phys. Discuss., 11, 22801-22856, doi:10.5194/acpd-11-22801-2011, 2011.

Bundke, U., Nillius, B., Jaenicke, R., Wetter, T., Klein, H., and Bingemer, H.: The fast ice nucleus chamber FINCH, Atmos. Res., 90, 180-186, 2008.

Connolly, P. J., Möhler, O., Field, P. R., Saathoff, H., Burgess, R., Choularton, T., and Gallagher, M.: Studies of heterogeneous freezing by three different desert dust samples, Atmos. Chem. Phys., 9, 2805-2824, doi:10.5194/acp-9-2805-2009, 2009.

Cziczo, D. J., Murphy, D. M., Hudson, P. K., and Thomson, D. S.: Single particle measurements of the chemical composition of cirrus ice residue during crystal-face, J. Geophys. Res.-Atmos., 109, D04201, doi:10.1029/2003JD004032, 2004.

Cziczo, D. J., Froyd, K. D., Gallavardin, S. J., Möhler, O., Benz, S., Saathoff, H., and Murphy, D. M.: Deactivation of ice nuclei due to atmospherically relevant surface coatings, Environ. Res. Lett., 4, 1-9, 2009.

Cwiertny, D. M., Baltrusaitis, J., Hunter, G. J., Laskin, A., Scherer, M. M., and Grassian, V. H.: Characterization and acid mobilization study of iron containing mineral dust source materials, J. Geophys. Res., 113, D05202, doi:10.1029/2007JD009332, 2008.

DeMott, P. J., Cziczo, D. J., Prenni, A. J., Murphy, D. M., Kreidenweis, S. M., Thomson, D. S., Borys, R., and Rogers, D. C.: Measurements of the concentration and composition of nuclei for cirrus formation, P. Natl. Acad. Sci. USA, 100, 14655-14660, 2003a.

DeMott, P. J., Sassen, K., Poellot, M. R., Baumgardner, D., Rogers, D. C., Brooks, S. D., Prenni, A. J., and Kreidenweis, S. M.: African dust aerosols as atmospheric ice nuclei, Geophys. Res. Lett., 30, 1732, doi:10.1029/2003GL017410, 2003b.

Drewnick, F., Hings, S. S., DeCarlo, P., Jayne, J. T., Gonin, M., Fuhrer, K., Weimer, S., Jimenez, J. L., Demerjian, K. L., Borrmann, S., and Worsnop, D. R.: A new Time-of-Flight Aerosol Mass Spectrometer (ToF-AMS)-instrument description and first field deployment, Aerosol Sci. Technol., 39, 637-658, doi:10.1080/02786820500182040, 2005.

Eastwood, M. L., Cremel, S., Wheeler, M., Murray, B. J., Girard, E., and Bertram, A. K.: Effects of sulfuric acid and ammonium sulfate coatings on the ice nucleation properties of kaolinite particles, Geophys. Res. Lett., 36, L02811, doi:10.1029/2008GL035997, 2009.

Findeisen, W.: Die kolloidmeteorologischen Vorgänge bei der Niederschlagsbildung, Meteorologische Z., 55, 121-133, 1938.

Hartmann, S., Niedermeier, D., Voigtländer, J., Clauss, T., Shaw, R. A., Wex, H., Kiselev, A., and Stratmann, F.: Homogeneous and heterogeneous ice nucleation at LACIS: operating principle and theoretical studies, Atmos. Chem. Phys., 11, 17531767, doi:10.5194/acp-11-1753-2011, 2011.

Hoose, C., Kristjansson, J. E., Chen, J. P., and Hazra, A.: A classical-theory-based parameterization of heterogeneous ice nucleation by mineral dust, soot, and biological particles in a global climate model, J. Atmos. Sci., 67, 2483-2503, 2010.

$\mathrm{Hu}, \mathrm{X}$. L., and Michaelides, A.: Ice formation on kaolinite: lattice match or amphoterism?, Surf. Sci., 601, 5378-5381, 2007.

Hung, H. M., Malinowski, A., and Martin, S. T.: Kinetics of heterogeneous ice nucleation on the surfaces of mineral dust cores inserted into aqueous ammonium sulfate particles, J. Phys. Chem. A, 107, 1296-1306, 2003.

Kanji, Z. A., Florea, O., and Abbatt, J. P. D.: Ice formation via deposition nucleation on mineral dust and organics: dependence of onset relative humidity on total particulate surface area, Environ. Res. Lett., 3, 025004, doi:10.1088/1748-9326/3/2/025004, 2008.

Knippertz, P., Ansmann, A., Althausen, D., Müller, D., Tesche, M., Bierwirth, E., Dinter, T., Müller, T., Von Hoyningen-Huene, W., Schepanski, K., Wendisch, M., Heinold, B., Kandler, K., Petzold, A., Schütz, L., and Tegen, I.: Dust mobilization and transport in the Northern Sahara during SAMUM 2006 - a meteorological overview, Tellus B, 61, 12-31, 2009.

Knopf, D. A. and Koop, T.: Heterogeneous nucleation of ice on surrogates of mineral dust, J. Geophys. Res.-Atmos., 111, D12201, doi:10.1029/2005JD006894, 2006.

Knutson, E. O. and Whitby, K. T.: Aerosol classification by electric mobility: apparatus, theory and applications, J. Aerosol Sci., 6, 443-451, 1975.

Lasaga, A. C.: Fundamental approaches in describing mineral dissolution and precipitation rates, in: Chemical Weathering Rates of Silicate Minerals, Vol. 31 of Reviews in Mineralogy, Mineralogical Society America, Washington, USA, 23-86, 1995.

Lohmann, U. and Diehl, K.: Sensitivity studies of the importance of dust ice nuclei for the indirect aerosol effect on stratiform mixed-phase clouds, J. Atmos. Sci., 63, 968-982, doi:10.1175/JAS3662.1, 2006.

Lohmann, U. and Hoose, C.: Sensitivity studies of different aerosol indirect effects in mixed-phase clouds, Atmos. Chem. Phys., 9, 8917-8934, doi:10.5194/acp-9-8917-2009, 2009.

Martin, S. T.: Phase transitions of aqueous atmospheric particles, Chem. Rev., 100, 3403-3453, 2000.

Mason, B. J.: Ice-nucleating properties of clay minerals and stony meteorites, Q. J. Roy. Meteorol. Soc., 86, 552-556, 1960.

Murray, B. J., Wilson, T. W., Dobbie, S., Cui, Z., AlJumur, S. M. R. K., Möhler, O., Schnaiter, M., Wagner, R., Benz, S., Niemand, M., Saathoff, H., Ebert, V., Wagner, S., and Kärcher, B.: Heterogeneous nucleation of ice particles on glassy aerosols under cirrus conditions, Nature Geosci., 3, 233-237, 2010.

Murray, B. J., Broadley, S. L., Wilson, T. W., Atkinson, J. D., and Wills, R. H.: Heterogeneous freezing of water droplets containing kaolinite particles, Atmos. Chem. Phys., 11, 4191-4207, doi:10.5194/acp-11-4191-2011, 2011.

Niedermeier, D., Hartmann, S., Shaw, R. A., Covert, D., Mentel, T. F., Schneider, J., Poulain, L., Reitz, P., Spindler, C., Clauss, T., Kiselev, A., Hallbauer, E., Wex, H., Mildenberger, K., and Stratmann, F.: Heterogeneous freezing of droplets with immersed mineral dust particles - measurements and parameterization, Atmos. Chem. Phys., 10, 3601-3614, doi:10.5194/acp-10- 
3601-2010, 2010.

Niedermeier, D., Shaw, R. A., Hartmann, S., Wex, H., Clauss, T., Voigtländer, J., and Stratmann, F.: Heterogeneous ice nucleation: exploring the transition from stochastic to singular freezing behavior, Atmos. Chem. Phys., 11, 8767-8775, doi:10.5194/acp11-8767-2011, 2011.

Prather, A. K., Nordmeyer, T., and Salt, K.: Real-time characterization of individual aerosol particles using Time-of-Flight Mass Spectrometry, Anal. Chem., 66, 1403-1407, 1994.

Posfai, M., Anderson, J. R., Buseck, P. R., Shattuck, T. W., and Tindale, N. W.: Constituents of a remote pacific marine aerosol - a tem study, Atmos. Environ., 28, 1747-1756, 1994.

Prospero, J. M.: Long-term measurements of the transport of African mineral dust to the Southeastern United States: implications for regional air quality, J. Geophys. Res.-Atmos., 104, 15917-15927, 1999.

Pruppacher, H. R. and Klett, J. D.: Microphysics of Clouds and Precipitation, Kluwer Academic Publishers, Dordrecht, The Netherlands, 329pp., 1997.

Reitz, P., Spindler, C., Mentel, T. F., Poulain, L., Wex, H., Mildenberger, K., Niedermeier, D., Hartmann, S., Clauss, T., Stratmann, F., Sullivan, R. C., DeMott, P. J., Petters, M. D., Sierau, B., and Schneider, J.: Surface modification of mineral dust particles by sulphuric acid processing: implications for ice nucleation abilities, Atmos. Chem. Phys., 11, 7839-7858, doi:10.5194/acp11-7839-2011, 2011.

Richardson, M. S., DeMott, P. J., Kreidenweis, S. M., Cziczo, D. J., Dunlea, E. J., Jimenez, J. L., Thomson, D. S., Ashbaugh, L. L., Borys, R. D., Westphal, D. L., Casuccio, G. S., and Lersch, T. L.: Measurements of heterogeneous ice nuclei in the Western United States in springtime and their relation to aerosol characteristics, J. Geophys. Res.-Atmos., 112, D02209, doi:10.1029/2006JD007500, 2007.

Roberts, G. C. and Nenes, A.: A continuous-flow streamwise thermal-gradient $\mathrm{CCN}$ chamber for atmospheric measurements, Aerosol Sci. Technol., 39, 206-221, 2005.

Rogers, D. C.: Development of a continuous flow thermal gradient diffusion chamber for ice nucleation studies, Atmos. Res., 22, 149-181, doi:10.1016/0169-8095(88)90005-1, 1988.

Sassen, K., DeMott, P. J., Prospero, J. M., and Poellot, M. R.: Saharan dust storms and indirect aerosol effects on clouds: crystal-face results, Geophys. Res. Lett., 30, 1633, doi:10.1029/2003GL017371, 2003.

Seifert, P., Ansmann, A., Mattis, I., Wandinger, U., Tesche, M., Engelmann, R., Müller, D., Pérez, C., and Haustein, K.: Saharan dust and heterogeneous ice formation: eleven years of cloud observations at a Central European EARLINET site, J. Geophys. Res., 115, D20201, doi:10.1029/2009JD013222, 2010.
Stetzer, O., Baschek, B., Lüönd, F., and Lohmann, U.: The Zurich Ice Nucleation Chamber (ZINC) - a new instrument to investigate atmospheric ice formation, Aerosol Sci. Technol., 42, 6474, 2008.

Stratmann, F., Kiselev, A., Wurzler, S., Wendisch, M., Heintzenberg, J., Charlson, R. J., Diehl, K., Wex, H., and Schmidt, S. Laboratory studies and numerical simulations of cloud droplet formation under realistic supersaturation conditions, J. Atmos. Ocean. Tech., 21, 876-887, 2004.

Sullivan, R. C., Petters, M. D., DeMott, P. J., Kreidenweis, S. M., Wex, H., Niedermeier, D., Hartmann, S., Clauss, T., Stratmann, F., Reitz, P., Schneider, J., and Sierau, B.: Irreversible loss of ice nucleation active sites in mineral dust particles caused by sulphuric acid condensation, Atmos. Chem. Phys., 10, 1147111487, doi:10.5194/acp-10-11471-2010, 2010a.

Sullivan, R. C., Minambres, L., DeMott, P. J., Prenni, A. J., Carrico, C. M., Levin, E. J. T., and Kreidenweis, S. M.: Chemical processing does not always impair heterogeneous ice nucleation of mineral dust particles, Geophys. Res. Lett., 37, doi:10.1029/2010GL045540, 2010b.

Vlasenko, A., Sjogren, S., Weingartner, E., Gaggeler, H. W., and Ammann, M.: Generation of submicron Arizona test dust aerosol: chemical and hygroscopic properties, Aerosol Sci. Technol., 39, 452-460, 2005.

Wiacek, A., Peter, T., and Lohmann, U.: The potential influence of Asian and African mineral dust on ice, mixed-phase and liquid water clouds, Atmos. Chem. Phys., 10, 8649-8667, doi:10.5194/acp-10-8649-2010, 2010.

Wex, H., Clauss, T., Covert, D., Hallbauer, E., Hartmann, S., Kiselev, A., Mentel, T. F., Mildenberger, K., Niedermeier, D., Poulain, L., Reitz, P., Schneider, J., Shaw, R., Spindler, C., and Stratmann, F.: Classifying coated and uncoated arizona test dust with respect to hygroscopic growth and activation, in preparation, 2011.

Zimmermann, F., Weinbruch, S., Schutz, L., Hofmann, H., Ebert, M., Kandler, K., and Worringen, A.: Ice nucleation properties of the most abundant mineral dust phases, J. Geophys. Res., 113, D23204, doi:10.1029/2008jd010655, 2008.

Zobrist, B., Marcolli, C., Peter, T., and Koop, T.: Heterogeneous ice nucleation in aqueous solutions: the role of water activity, J. Phys. Chem. A, 112, 3965-3975, 2008. 